\title{
Accident Analysis and Prevention Measure of Dynamic Load Mine Pressure of the 31201 Fully Mechanized Working Face of Shigetai Coal Mine
}

\author{
Yingjie Liu* \\ College of Highway, Chang'an University, Xi'an, Shaanxi, China \\ Shenhua Shendong Coal Group Corporation, Shenmu, Shaanxi, China
}

Xiaomou Wang

College of Highway, Chang'an University, Xi'an, Shaanxi, China

\begin{abstract}
In order to eliminate the potential safety hazard of concentrated coal pillar of overlying coal seam occurring in the extraction process of 31201 fully mechanized working face of Shendong Shigetai coal mine, we formulate safety measures for the next extraction by analyzing the pressure data collected by the hydraulic support in the extraction process. According to research results, there exists irregular room-mining goaf of Coal 22 above Coal 31, and the existing concentrated coal pillar and scattered coal pillar in room-mining goaf parallel to the working face may cause the fully mechanized working face to form secondary roof structure, moreover, the primary reason for large-area roof fall accident is that the concentrated coal pillar of Coal 22 is destroyed and loses stability, thus leading to the dynamic load in the extraction process of Coal 31 . We analyze the data of the extraction process of Coal 31 through technical measures such as pressure observation, micro-seismic monitoring, multiple position extensometer inside stratum and surface observation, aiming at the reason for roof fall; and we formulate a set of complete prevention measures, aiming at overlying goaf and extraction pressure of this working face, so as to offer effective safety guarantee for the next extraction of this working face and also offer reference for the extraction of similar working faces.
\end{abstract}

Keywords: fully mechanized working face; overlying goaf; concentrated coal pillar; dynamic load mine pressure; hidden danger management

\section{FOREWORD}

The room and pillar mining is a widely-used mining technology, having a long history due to the relatively low level of technical equipment since the early period of coal mining. Through enhancing the stoping, improving the roof management and optimizating the supporting design, Damogou coal mine realized the safe stoping. The mine pressure of Bulianta coal mine 22303 large mining height face is affected by the above overbite coal pillar. The research employed the GSJ-1 Mine Pressure tester and ZYDC single hydraulic prop to monitor and analyze the reliability and applicability of the timbering equipment of the face. The scope of mining influence and the law of supporting pressure distribution are also determined, providing reference for the support pattern when cross the overbite coal pillar.

Huainan Pan'er Coal mine conducted the research of the effect of above overbite coal mining to the supporting pressure of the 18516 face. Numerical analysis software is used to analyze the mechanism of surrounding rock stress field distribution angle. The result shows, the biggest circulating end resistance is bigger than the supporting load under goaf.
Due to the high supporting pressure, the phenomenon of rib spalling and roof fall is much easier to happen when this position is mined.

The 31201 face is 311.4 meters with 1865 advancing length, coal thickness of $4.0 \mathrm{~m}$ and buried depth which is in the range of $103-137 \mathrm{~m}$. Its immediate roof consists of the fine sandstone which is in the range of $3.6-5.3 \mathrm{~m}$ and the main roof consists of sandstone which is in the range of $12-35.2 \mathrm{~m}$. The unconsolidated layers thickness is in the range of $0-51 \mathrm{~m}$, the bedrock thickness is in the range of $48-120 \mathrm{~m}$ and the spacing between the 31 coal seam and the 22 coal seam is in the range of $30-41.8 \mathrm{~m}$. According to the geological data, affected by the room and pillar mining goaf and overbite coal pillar, 3 kinds of hidden troubles may cause accident during stoping process. The first one is the dynamic load mine pressure which may push the hydraulic support down, and break off the high pressure spray and the tube. These phenomena may cause breakdown of equipment. The second trouble is that a lot of harmful gas may rush in the mining face when the roof of the 22 coal seam has a large-area collapse, which may cause workers to suffer the asphyxia. The third trouble is that above the overbite coal, the contained water may cause water disaster.

*Corresponding author: 290785858@qq.com

This is an Open Access article distributed under the terms of the Creative Commons Attribution License 4.0, which permits unrestricted use, distribution, and reproduction in any medium, provided the original work is properly cited. 
MATEC Web of Conferences

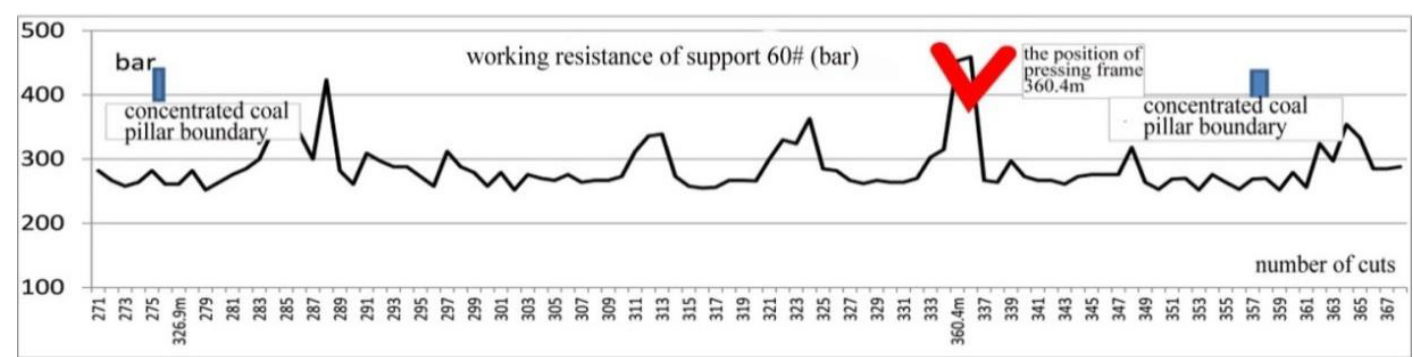

(a)

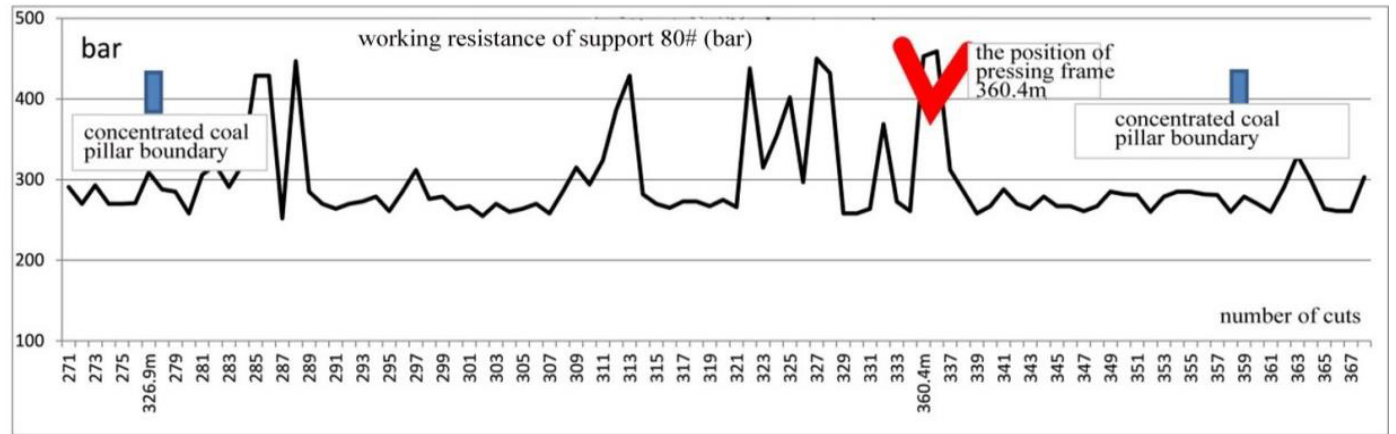

(b)

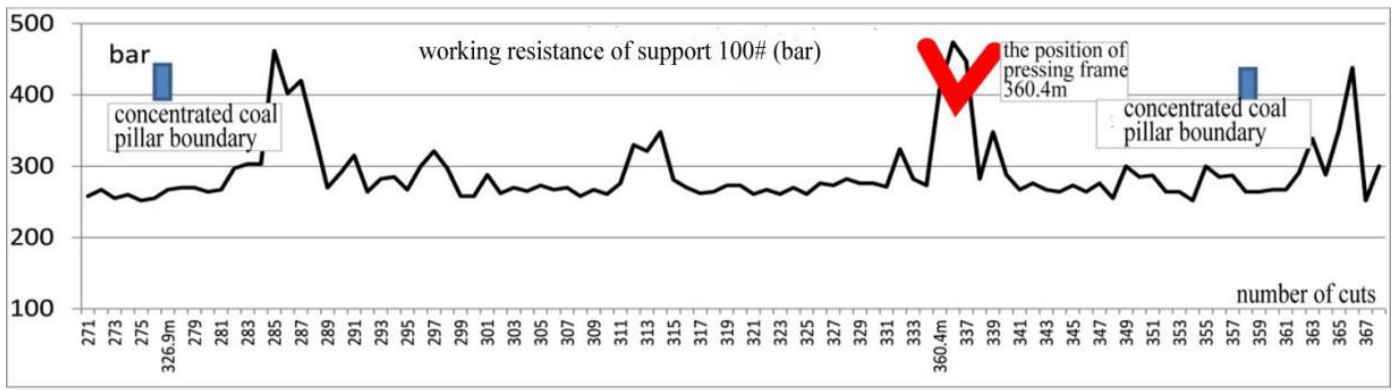

(c)

Figure 1. First pressure occurred in abnormal situation

2 CHARACTERISTICS AND CAUSE ANALYSIS OF STOPING PROCESS GETTING STARTED

\subsection{Manifestation characteristics of mine pressure}

The face roof pressure is not obvious in the first mining stage. It is raised to 458bar when the mining advances to $40.8 \mathrm{~m}$ and continues 10 cutting circuits. Rib spalling and safety valve opening $(10 \%)$ are happened partially; the column subsidence has not been found; the pressure drawing pace is $48.6 \mathrm{~m}$.

The average pressure drawing pace is $13.6 \mathrm{~m}$, continuing average 7.7 cutting circuits in the pressure section while it continuing average 10.3 cutting circuits in pressure free section, and the pressure peak reached 465 bar when the pressure coming. Several phenomena occur when the roof pressure coming, such as fracture, rib spalling, roof slag dropping, stone leak, safety valve opening rate which is between $5 \%$ $15 \%$, and the column subsidence which is less than $0.2 \mathrm{~m}$. The roof pressure on the two endings of mining face and crossheading is not obvious, big fracture has also not occurred, and some fish scale like structure on the roof can be found.

By the end of December $16^{\text {th }}, 2013$, the mining face had been increased to $773 \mathrm{~m}$. During this period, the pressure had showed 3-times peaks.

(1) The first time is on October $17^{\text {th }}, 2013$, when the mining face was increased to $360.4 \mathrm{~m}$, the supports No. $40 \#-120 \#$ showed the large-area roof pressurization. The average pressure reached $458 \mathrm{bar}$, and the columns produced $0.4-1.3 \mathrm{~m}$ subsidence, leading to the breakdown of 5 supports.

(2)The second time is on November $25^{\text {th }}, 2013$. The average pressure reached 513bar, and the supports $65^{\#}$ 
$110^{\#}$ experienced subsidence which is in the range of $0.3-1.2 \mathrm{~m}$.
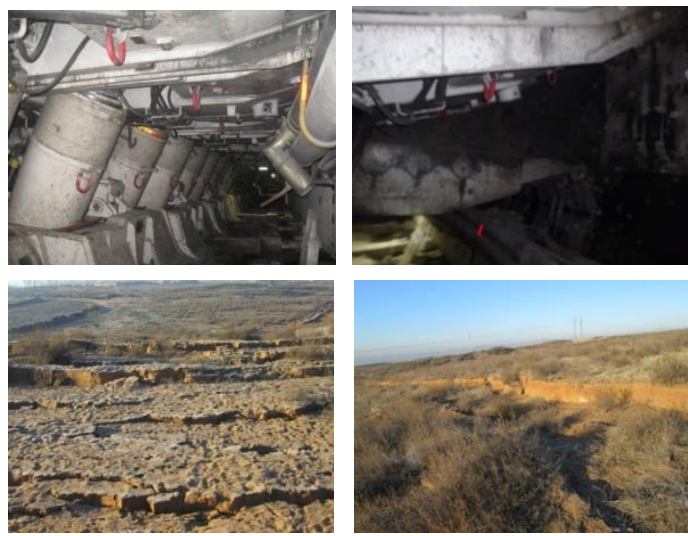

Figure 2. Surface crack and support are pushed down and not in extensible situation

(3)The third time occurred on December $16^{\text {th }}, 2013$, when the mining face was increased in the range of $771.4-775.6 \mathrm{~m}$, the supports No. $23^{\#}-135^{\#}$ experienced large-area roof pressurization. The column cylinder stroke was decreased from the range of $1.3-1.5 \mathrm{~m}$ to the range of $0-0.2 \mathrm{~m}$, leading to 121 supports out of extensile capability.
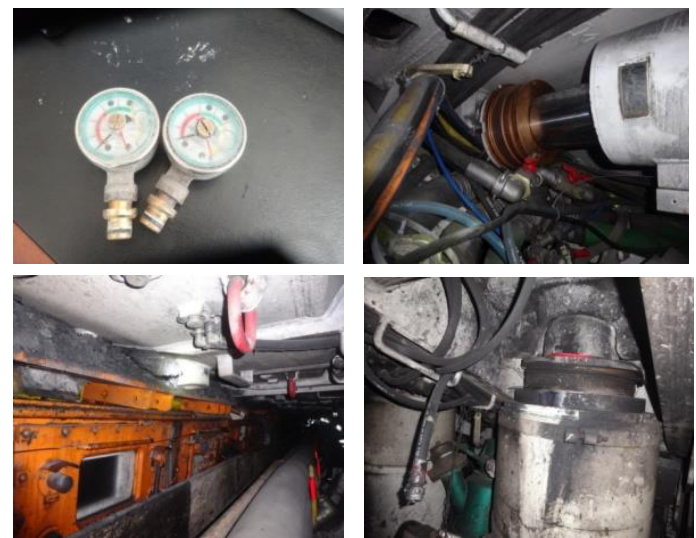

Figure 3. Equipment trouble situation

In the third accident, several equipment are broken down. The broken equipment and parts including 200 columns, 20 balance cylinders, 21 sprag rams, 484 safety valves, 206 pressure gauges, and other 100 valve blocks, 1000 parts and structural components, 1200 pipe connecting parts.

\subsection{Cause analysis of abnormal pressure that occurs on working face}

The abnormal pressure occurs on working face for three times, it is in and out of overbite coal pillar of 22 coal room collection. Because there existed irregular 22 coal room collection above the stope face for $37 \mathrm{~m}$ (it's 9.25 times the mining height) based on the analysis. The existing overbite coal pillar and scattered coal pillar of the pillar and breast method gob that parallel to the working face may cause fully mechanized coal mining face to be the secondary roof structure. Influenced by stopping mining moves, the instability and failure of overbite coal pillar caused the dynamic loading phenomenon and the abnormal 31201working face pressure.

\section{DYNAMIC LOAD PRESSURE MONITOR- ING AND MANAGEMENT}

\subsection{Dynamic load pressure monitoring}

Using the methods of the pressure observation, the microseismic monitoring, the interior rock layer displacement monitoring and the surface crack observation are used to predict dynamic load in order to take unloading blast in compulsory measures to carry on comprehensive control dynamic load.

(1) Pressure observation

We analyze the roof movement step and the support applicability of the working face by means of the original mine pressure transmission system of working face and the manual monitoring.

(2) Micro-seismic monitoring

According to the structure and composition of KJ768 micro-seismic monitoring system, two down hole monitoring stations are arranged for the 31201 working face, one being at the air return gateway and the other being at the conveying gateway; measuring points are arranged from the position being $1034 \mathrm{~m}$ away from the withdrawal entry to the withdrawal entry, and a total of 31 moveable measuring points are set on each gateway, with the spacing being $30 \mathrm{~m} ; 15$ fixed measuring points are set on the roof, with the spacing being $60 \mathrm{~m} ; 31$ fixed measuring points are set on the baseboard, with the spacing being $30 \mathrm{~m}$; all the measuring points arranged amount to 154 , as shown in Figure 2.

By monitoring and predicting the total quantity, total energy and positions of micro-seismic events for many times, we work out the judging indexes of energy maximums of Coal 31 periodic weighting and Coal 22 dynamic load mine pressure, that is, the warning index of Coal 31 periodic weighting is micro-seismic event quantity being over 15 and the total energy being $4.2 * 105 \mathrm{~J}$, and the warning index of Coal 22 dynamic load mine pressure is micro-seismic event quantity being over 31 and total energy being $8.0 * 105 \mathrm{~J}$; based on this, we judge the energy change and breakage degree of roof and baseboard of any area so as to reach the purpose of warning.

Four holes being $110 \mathrm{~mm}$ in diameter and $80 \mathrm{~m}$ in depth are drilled from ground to the inside of stratum, on both sides of concentrated coal pillar, in the ad- 


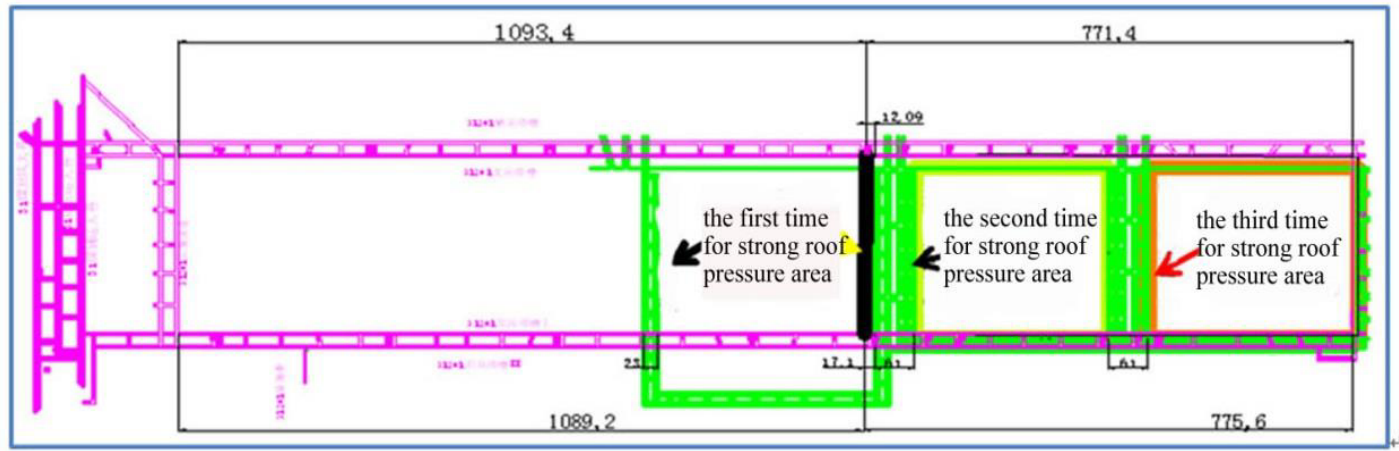

Figure 4. Working face occur for three times in abnormal pressure situation

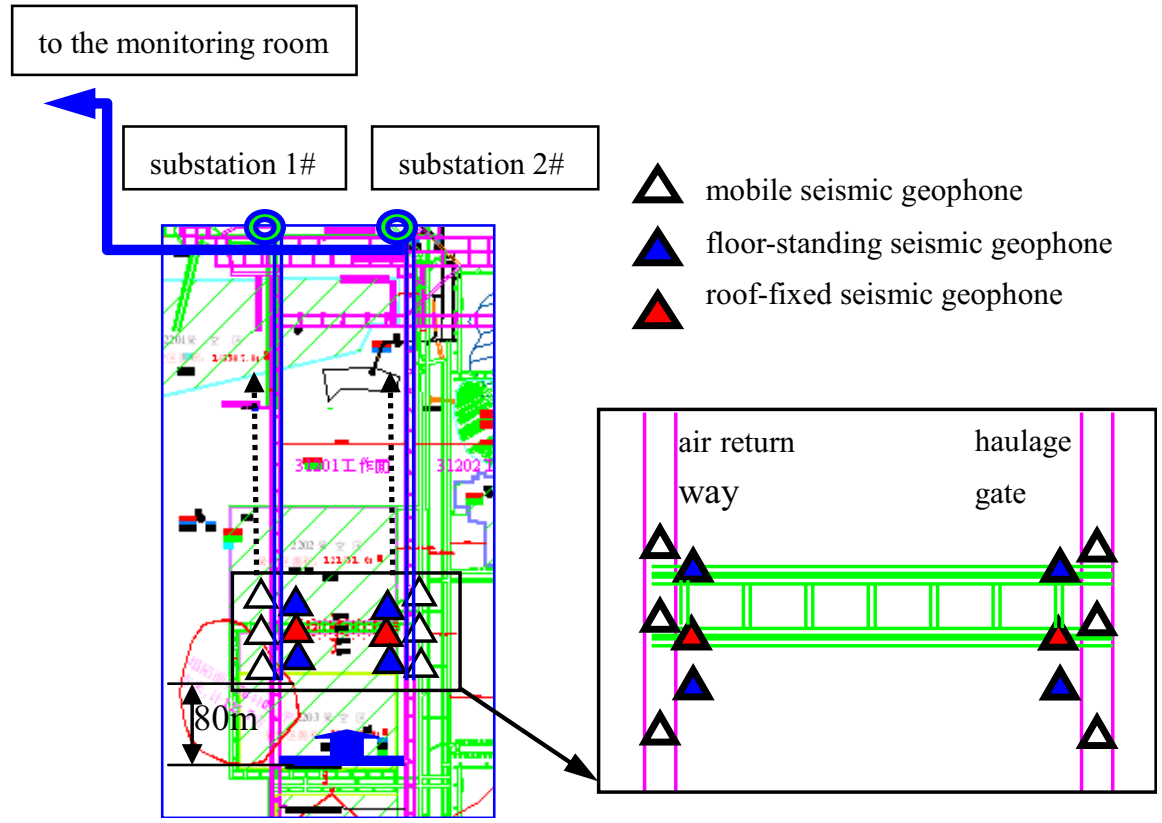

Figure 5. Layout schematic plan of working face seismic monitoring

vancing direction of working face and with the spacing being $30 \mathrm{~m}$; observation points are set at different depths of drill hole and nearby contact area of stratum of each layer; automatic monitoring system is used to carry out real-time dynamic monitoring on the displacement of stratum of different layers; monitoring data are collected through wireless transmission network once every $15 \mathrm{~min}$ and sent back to the monitoring center.

We can analyze the Coal 22 roof movement in the process of advance of 31201 working face and Coal 22 roof falls after the forced blasting.

When the working face is advanced to the position being $15 \mathrm{~m}$ away from observation hole $1 \#$, the Coal 22 roof breakage should be noticed timely. If the data doesn't change obviously (the subsidence value of sensor1\# being less than $0.5 \mathrm{~m}$ ) when the working face is advanced to the position of observation hole2\#, this shows that the area of suspension roof of Coal 22 is so large as to reach the limit and that the roof of Coal 22 must be disposed right away.

When the working face is advanced to the position being $15 \mathrm{~m}$ away from observation hole $2^{\#}$, the Coal 22 roof will be breakage; with the advance of working face, when it is $20 \mathrm{~m}$ away from the concentrated coal pillar, the first presplitting blasting of working face is carried out. With the advance of working face, it's necessary to timely observe the value change of displacement meter of drill hole; when the distance from the observation hole2\# to the working face exceeds suspension roof for $20 \mathrm{~m}$, the suspension roof problem of Coal 22 goaf must be solved; this shows that the 


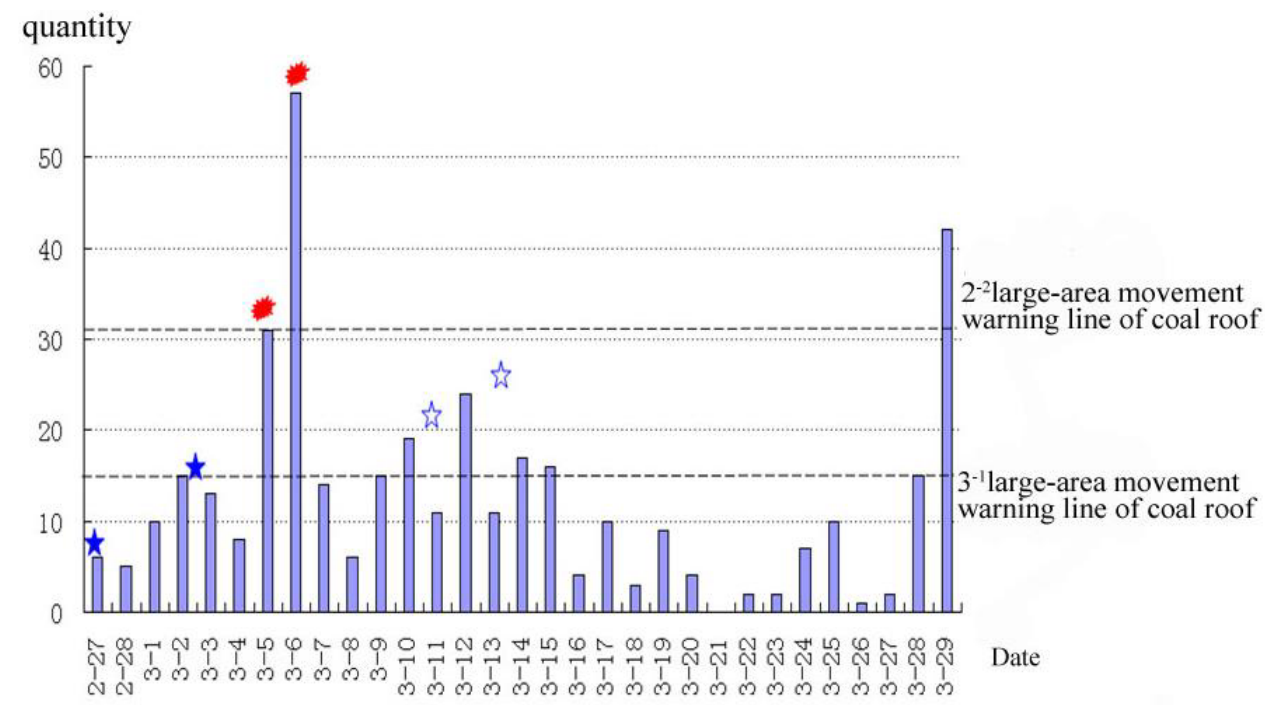

Figure 6. Early warning diagram of the number of microseismic event

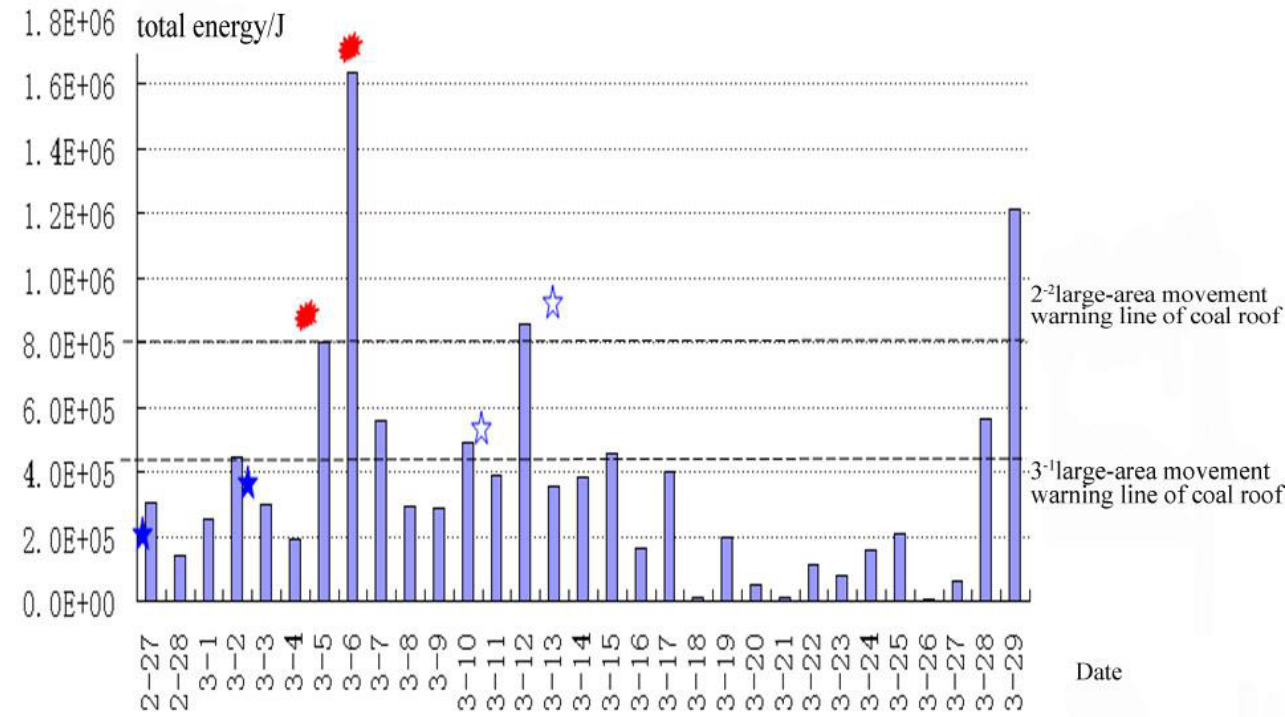

Figure 7. Early warning diagram of microseismic event total energy

effect of presplitting blasting of working face is not obvious, and it is suggested that the method of blasting and caving Coal 22 roof be adopted.

If the blasting effect achieves expectation, that is, the Coal 22 roof doesn't have large-area suspension roof (suspension roof being less than $30 \mathrm{~m}$ ), a comprehensive analysis should be carried out combining the mine pressure of micro-seism on working face when the working face is smoothly advanced to observation holes $3 \#$ and $4 \#$.

(4) Borehole television observation
The borehole color television color system can carry out observation and record on various features and subtle variations of geological bodies within drill hole by means of the waterproof camera probe with light source, which is placed in underground drill hole. It can observe the completeness of overlying stratum of coal, the growth characteristics of preexisting fracture and the fracture development width and connection of stratum within fracture zone of mined rock mass.

One observation point is set on Group 3 concentrated coal pillar and one at the position being $60 \mathrm{~m}$ 


\section{MATEC Web of Conferences}

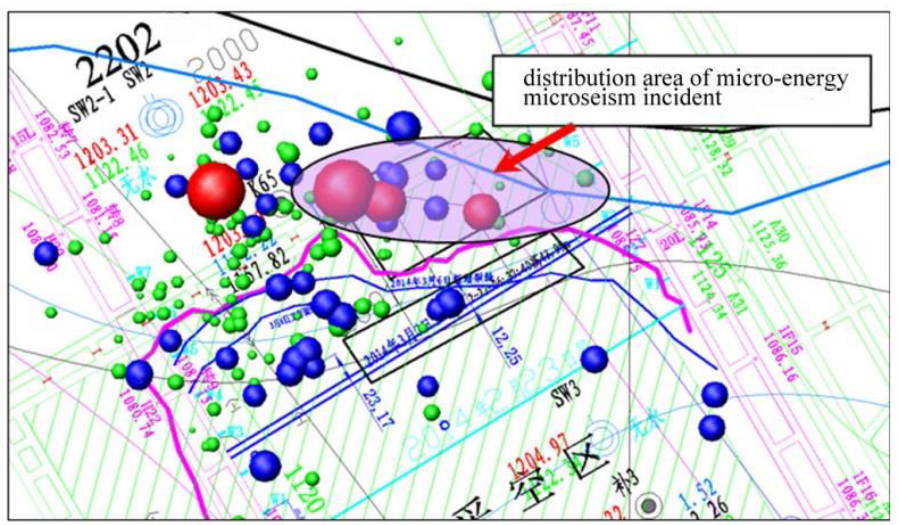

Figure 8. Early warning diagram of seismic monitoring

ahead in the advancing direction of working face, that is, multiple position extensometer $1^{\#}$ and $3^{\#}$ are used to carry out observation.

Through the observation of drill hole TV, it is worked out that the Coal 22 roof has no breakage or damage and it is comparatively completed nearby holes $1^{\#}$ and $3^{\#}$. It is shown in the following Figure 9:
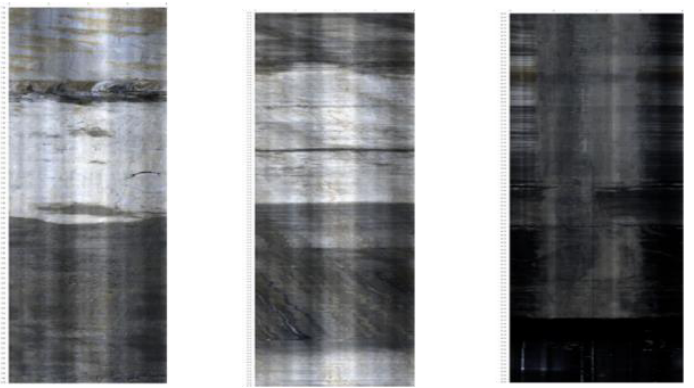

Figure 9. Results of No.1 borehole television (they were respectively in the range of $7-10 \mathrm{~m}, 16-22 \mathrm{~m}$ and $80-84 \mathrm{~m}$ )

\section{(5) Surface observation}

Ten stratum displacement observation lines numbered as $\mathrm{C}-\mathrm{L}$ are arranged on the surface in the direction of working face, and five observation points are arranged on each observation line. Observation points are arranged on the surface above the working face separate pillar forward and backward. The subsidence and breakage of Coal 22 roof and Coal 31 roof in the advancing process of the 31201 working face is judged through observation on surface fracture and subsidence.

Observe surface fracture and subsidence of 31201 working face every day, and carry out sorting-out analysis and real-time update on monitoring data timely.

Summarize and analyze means such as mine pressure monitoring analysis, micro-seismic monitoring, surface rock shift rule observation, ground hole multi- ple position extensometer observation and drill hole TV observation every day, and form guiding opinions on dynamic load mine pressure prevention of 31201 working face.

(6) Blasting of overlying concentrated coal pillar Before overlying concentrated coal pillar is approached, it should be carried out the forced blasting to destroy its completeness and release a great quantity of elastic energy generated due to the pressure aggregation and reduce the impact and damage on support caused when the roof has breakage due to the influence of mining moves. The specific schemes are as follows: First, stop mining when the working face is advanced to the position being around $30 \mathrm{~m}$ away from overlying concentrated coal pillar, meanwhile, adjust the mining height to $4.0 \mathrm{~m}$, and set up blast holes for forced blasting in the middle of working face; the center line of blast holes is located at the position being $0.5 \mathrm{~m}$ away from the roof of working face, and a total of 36 blast holes are arranged like “-”shape, spacing being $6 \mathrm{~m}$, angle being 45 degrees, and depth of each hole being $68 \mathrm{~m}$; second, adopt water-gel explosive or emulsion matrix explosive and fill $20 \mathrm{~m}$ of each hole with explosive, explosive load for each meter of blasthole being $3.6 \mathrm{Kg}$, explosive load for each blast hole being $72 \mathrm{Kg}$, and $2592 \mathrm{Kg}$ of explosive being needed totally.

If the hidden danger of dynamic load mine pressure can't be effectively eliminated after the above blasting measures have been taken, then it's necessary to punch holes on ground to implement blasting and pressure relief on Coal 22 roof.

Carry out warning on the extraction under goaf of room-mining and carry out evaluation on the effect of forced blasting of overlying concentrated coal pillar by analyzing and processing the data obtained by mine pressure observation, micro-seismic monitoring, stratum inside multiple position extensometer and surface observation. If the reading of extensometer is more than $0.5 \mathrm{~m}$, then the energy range shown by micro-seismic monitoring is no more than the previous observation index, and the pressure appearance and 


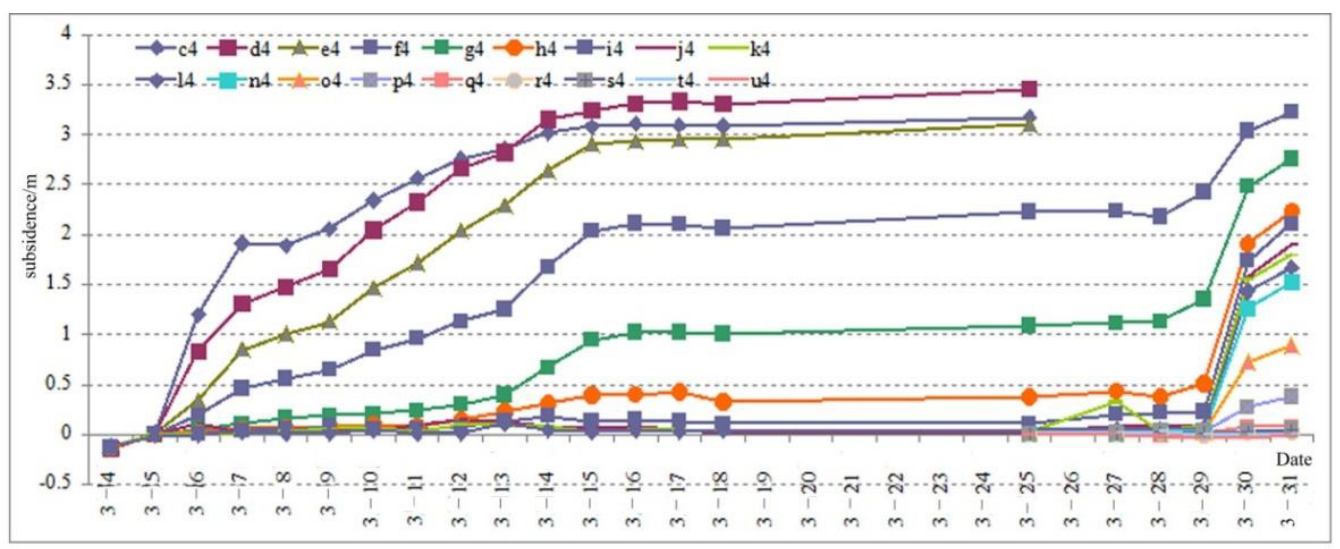

Figure 10. Surface subsidence observation situation

surface subsidence are normal, thus carrying out advancing normally; if the reading of extensometer is less than $0.5 \mathrm{~m}$ and the energy range shown by $\mathrm{mi}$ cro-seismic monitoring is more than the previous observation index, we analyze mine pressure rule and surface subsidence, determine safe advancing distance according to periodic weighting pace and then arrange holes newly to carry out forced blasting of overlying concentrated coal pillar.

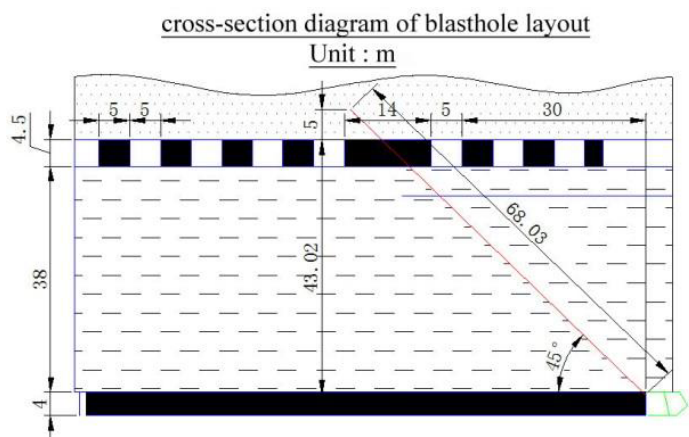

Figure 11. 31201 Working face overlying coal pillar concentrated blast-hole sections layout

\subsection{Roof control}

(1) Determination and control on mining height When overlying coal pillar is passed, the mining height is at least $3.8 \mathrm{~m}$ (except the transition Support 10 for both ends) and it is higher than that for normal extraction so as to prevent the occurrence of situations such as surge pressure formed by the roof causing transient pillar to sink and small stroke causing support to be pushed down. The driver of coal machine cuts bottom along the roof in the process of coal-cutting for mining height control to ensure the completeness of roof; mining height should be also ensured when construction is encountered.
(2) Each shift is notified of the relative position of working face with solid coal pillar at the pre-shift meeting to make all the personnel know the overall condition of working face. At the time of the pressure occur on the working face partially or wholly, the mine dispatching room should be timely contacted to prepare storage position and ensure normal production; when the coal machine is stopped, the roller should be lowered to the lowest part of baseboard.

(3) When the section of concentrated coal pillar is passed in the process of extraction, the support worker should pull the support based on the front roller of coal machine to control the roof; in case of roof breakage, the method of pressure advancing of support or sliding advancing of support is adopted to reduce the damage on the roof, and the fore support pulling or other modes are adopted to control beam-end distance; the beam-end distance should be no more than $580 \mathrm{~mm}$ to prevent the occurrence of collapsed rock in front of support; when the beam-end distance exceeds $580 \mathrm{~mm}$, the manual adjustment should be carried out and the method of fore support pulling should be adopted to carry out control.

(4) The roof management of two gateways should be strengthened, especially in the area of advance support; each shift should inspect the first support force of single object and change the damaged single object timely. The supporting intensity of roof and both sides should be strengthened. For the sections of two gateways which are too high or have roof fall, during the extraction of fully mechanized face, an effective advance support must be used and the end support should contact the roof closely.

(5) Each shift should observe the periodic weighting of the main roof, the area of suspension roof after supporting and the pressure behavior of working face, do shift record well and report to the operator on duty after rising. Each shift must know the periodic weighting and pressure behavior in the previous three shifts and carry out work arrangement and key task assignment at the pre-shift meeting according to the 


\section{MATEC Web of Conferences}

prediction and forecast on periodic weighting by the mine pressure observation group.

(6) During the concentrated coal pillar is passed, the leading or lagging amount of machine head and machine tail should be controlled reasonably, with the air return gateway and conveying gateway of 31201 working face being $1865 \mathrm{~m}$; the number of knives added and the position of knife adding should be controlled well at the time of slope adjustment of working face in case of special situations; the angle of slope adjustment should be kept at 1-2.5 degrees, and the difference between footages of two ends may not exceed $13.7 \mathrm{~m}$

\subsection{Harmful gas prevention and control}

The connection and sealing of air return way and goaf adopts the method of "seeing two closing one" to ensure that one joint lane connected with goaf always exists to act as the pressure releasing pathway of goaf and reduce the pressure of gas in goaf on working face; one oxygen sensor should be respectively set at supports $30^{\#}, 60^{\#}, 90^{\#}$ and $120^{\#}$ of working face, which is connected with the amplified phone to realize voice alarm function (voice alarm saying "evacuating immediately"); when the oxygen concentration at any position within working face is lower than $18 \%$, it must be done to stop machine and evacuate people; in the intake air of working face, the oxygen concentration should be no less than $20 \%$, the concentration of carbon dioxide should be no more than $0.5 \%$ and the gas concentration should be no more than $0.5 \%$; the curtains of machine head and machine tail keeping out the wind should be hung up at any time to prevent hazardous gases including carbon monoxide at the corner of working face from exceeding the standard; during production, after the coal machine cuts triangle coal, the support worker should pull out the end support and cover the curtains closely to prevent gases at corner from exceeding the standard; the number of operators within working face and air return way should be minimized; a number of oxygen breathing apparatus should be deposited within working face to be convenient for use in case of emergency; all the personnel entering working face should wear portable oxygen meter.

\subsection{Water disaster control}

Drainage water measure should be taken in advance for working face, and water level observation work sh- ould be strengthened; the drainage system of working face and two gateways should be perfected to ensure that the system runs reliably; meanwhile, double circuit power supply should be arranged to ensure that the power supply of drainage system is reliable.

\section{CONCLUSION}

(1) According to research results, there exists irregular room-mining goaf of Coal 22 above Coal 31, and the existing concentrated coal pillar and scattered coal pillar in room-mining goaf parallel to the working face may cause the fully mechanized working face to form secondary roof structure, moreover, the primary reason for large-area roof fall accident is that the concentrated coal pillar of Coal 22 is destroyed and loses stability, thus leading to dynamic load, in the extraction process of Coal 31 .

(2) We analyze the data of the extraction process of Coal 31 through technical measures such as pressure observation, micro-seismic monitoring, multiple position extensometer inside stratum and surface observation to reach the purpose of early warning; meanwhile, we avoid the dynamic load mine pressure from appearing by carrying out the forced blasting of overlying concentrated coal pillar to make it presplit according to the data analysis.

\section{REFERENCES}

[1] Li Zheng. 2013. Technology of rich mining of goaf overlying coal seams. Kunming: Yunnan Coal: 33-36.

[2] Wang Shidong. 2013. Coal pillar in working face pressure regularity and control measures. Energy Technology and Management 38(1):36-38.

[3] Hu Jinjian, Zhou Guangfei. \& Wu Xiaoming etc. 2012. Study on the mine pressure evolution of large mining height fully mechanized working face under near gob. Coal Engineering: 75-78.

[4] Qian Minggao. \& Shi Pingwu. 2003. Ming press and strata control. China University of Mining and Technology Press: 195-197.

[5] Ju Junfeng, Xu Jialin, Zhu Weibing, \& Wang Xiaozhen. 2010. Mechanism of dynamic load mine pressure from short distance coal seam working face to inclined coal pillar. Journal of China coal society 35(1):15-20.

[6] Wang Guowang. 2007. Rules and safety measures of mine pressure of Huojitu coal mine working face. Xi'an. Shaanxi Coal: 53-54. 